\title{
Kinetic Studies on the Enzyme-substrate Complex Formation of $p$-Hydroxybenzoate Hydroxylase by the Stopped-flow Method
}

\author{
Naoki Higashi, Hirohumi Shoun, Keiji Yano, and Kei Arima \\ Department of Agricultural Chemistry, Faculty of Agriculture, The University of Tokyo \\ and \\ Keitaro Hiromi \\ Department of Food Science and Technology, Faculty of Agriculture, Kyoto University \\ (. Naturforsch. 27 b, 1172-1175 [1972] ; received May 10, 1972)
}

Hydroxylase of $p$-Hydroxybenzoate, FAD- containing Monooxygenase, ES complex formation by Stopped-flow method, Relaxation analysis of ES complex formation of $p$-Hydroxybenzoate hydroxylase

\begin{abstract}
The spectrophotometric and spectrofluorometric investigations of the enzyme-substrate complex formation of $p$-hydroxybenzoate hydroxylase was made by the stopped-flow technique. The apparent velocity of the formation of the enzyme-substrate complex (the velocity of the absorbance change in visible and UV regions, and the velocity of the quenching of the fluorescence intensity in the FAD moiety of the holoenzyme by the substrate) was rapid enough to explain the maximal overall velocity $\left(72 \mathrm{sec}^{-1}\right)$ or the activated anaerobic reduction rate $\left(k_{\mathrm{red}}^{\max }=200 \mathrm{sec}^{-1}\right)$. The results were consistent with a two-step mechanism involving a rapid bimolecular association of enzyme and substrate, and a slower follow-up unimolecular process.
\end{abstract}

Abbreviations: FAD, flavin adinine dinucleotide; S, substrate, $p$-hydroxybenzoate; Eox, oxidized holoenzyme (Apoenzyme-FAD complex) ; Eox-S, holoenzyme-substrate complex (E-S complex).

p-Hydroxybenzoate hydroxylase [EC 1.14.1.12.] from Pseudomonas desmolytica IAM 1123, one of monooxygenases, contains one mole of FAD per mole of enzyme. In the presence of NADPH and molecular oxygen, $p$-hydroxybenzoate is hydroxylated to yield protocatechuate ${ }^{1}$. The overall reaction consists of three sequential reaction steps: the formation of enzyme-substrate complex, the reduction of the FAD moiety of the complex and the reoxidation of the enzyme with concomitant formation of the product. Each of them can be observed by separate addition of three substrates, i.e., $p$-hydroxybenzoate, NADPH and $\mathrm{O}_{2}{ }^{*}$ in this order ${ }^{3,4}$. It is difficult, in general, to obtain the enzyme-substrate complex without formation of its product, since the complex is transient and unstable. In the case of $p$-hydroxybenzoate hydroxylase, however, the enzyme-substrate complex can be obtained as a chemically stable crystalline state in the absence of NADPH ${ }^{1}$.

It was reported that the absorption spectrum of the holoenzyme changed by the addition of the sub-

Requests for reprints should be sent to N. HigasHI, Department of Agricultural Chemistry, Lab. of Fermentation and Microbiology, Faculty of Agriculture, The University of Tokyo, Tokyo 113, Japan. strate, $p$-hydroxybenzoate, and that the intensity of the fluorescence of the FAD moiety of the holoenzyme by the addition of $p$-hydroxybenzoate or its analogs. These changes are due to the formation of the complex between the enzyme and the substrate or substrate analog ${ }^{1,5}$. It was also reported that the binding of the substrate, $p$-hydroxybenzoate, to the active site of the enzyme caused a slight but distinct conformational change in enzyme molecule, and caused a remarkable increase in the rate of the anaerobic reduction of the FAD moiety $\left(k_{\mathrm{red}}\right.$ in the presence of $p$-hydroxybenzoate was 10,000 times larger than that in the absence of $p$-hydroxybenzoate ${ }^{3}$ ). This remarkable activation was considered as a result of the conformational change by the substrate binding ${ }^{4,6}$. It is important to investigate whether the velocity of the enzyme-substrate complex formation, the changes both in protein conformation and in the FAD moiety, is rapid enough to explain the overall velocity $(V / e=$ $72 \mathrm{sec}^{-1}$ ) or not.

This communication deals with the spectrophotometric and the spectrofluorometric investigations of the Eox-S complex (holoenzyme-p-hydroxybenzoate complex) formation by the stopped-flow method. A standard procedure for the relaxation method has

* Recently we detected new enzyme species during the presteady state of oxygenation process, these results will be published elsewhere ${ }^{2}$. 
been applied to analyze the results. It is shown that the velocity of the Eox-S complex formation is very rapid, and the complex formation consists of two reversible reactions.

The method used for the enzyme preparation was described previously ${ }^{1}$. All measurements were made at $25^{\circ} \mathrm{C}$ in a phosphate buffer, $0.05 \mathrm{M}, \mathrm{pH}=8.2$. The Eox-S complex formation was studied by using the change in absorption spectrum (see the difference spectrum: solid line in Fig. 3) by the use of a Yanagimoto stopped-flow spectrophotometer SPU-1 ${ }^{7}$. The Eox-S complex formation was also studied by using the quenching of the fluorescence due to the FAD moiety by the use of the same apparatus with a fluorescence equipment (excitation: $440 \mathrm{~nm}$, emission: above $480 \mathrm{~nm}$ with a Kenko filter Y-2). The dead-time of the apparatus was less than $1 \mathrm{msec}$. The details of the apparatus was described elsewhere ${ }^{8}$. Holoenzyme solution was mixed with an equal volume of $p$-hydroxybenzoate solution, and the time course of the absorbance changes at various wavelengths was simultaniously recorded on a storage oscilloscope and a pen recorder, and the fluorescence quenching was recorded similarly.

Observed changes were very rapid and no other slower phases were observed. The reaction curve regarded as a relaxation curve is shown in Fig. $1^{*}$. The direction of the absorbance changes at all wavelengths was in accord with that of the difference spectrum. Under these conditions, the pseudo-firstorder rate constant, $k_{\mathrm{app}}=630 \mathrm{sec}^{-1}$, was estimated from the half-time of the reaction curve near equi- librium. This value was several times larger than that of $V / e\left(=72 \mathrm{sec}^{-1}\right)$ and $k_{\mathrm{red}}^{\max }\left(=200 \mathrm{sec}^{-1}\right.$, maximal reduction rate in the presence of $p$-hydroxybenzoate ${ }^{4,6}$ ). Therefore, overall reaction is not limited by the Eox-S formation.

The rapid complexing of Eox and $\mathrm{S}$ was also confirmed by the fluorescence stopped-flow experiments. The reaction curve which was regarded as a relaxation curve is shown in Fig. 2. Under these conditions, the pseudo-firstorder rate constant, $k=$ $700 \mathrm{sec}^{-1}$, was calculated from the half-time of the reaction curve. This value was in good agreement with that obtained from the absorbance change. The details of these experiments will be described elsewhere.

About $50 \%$ of the Eox-S formation reaction was estimated to occur within the dead-time (about $1 \mathrm{msec})^{9}$. The total absorbance changes at various wavelengths corrected for the dead-time of the apparatus from the stopped-flow traces assuming that the reaction follows a simple bimolecular reaction are shown by open circles in Fig. 3. If the Eox-S formation follows a simple bimolecular reaction, the total absorbance changes should agree with the difference absorbance at all wavelengths. In visible wavelength region the total absorbance changes agreed with the difference absorbance in the difference spectrum considerably well. In UV region, however, the observed absorbance changes wert about one third of the absorbance in the difference spectrum shown by the solid line in Fig. 3. In other words, two thirds of the absorbance change has oc

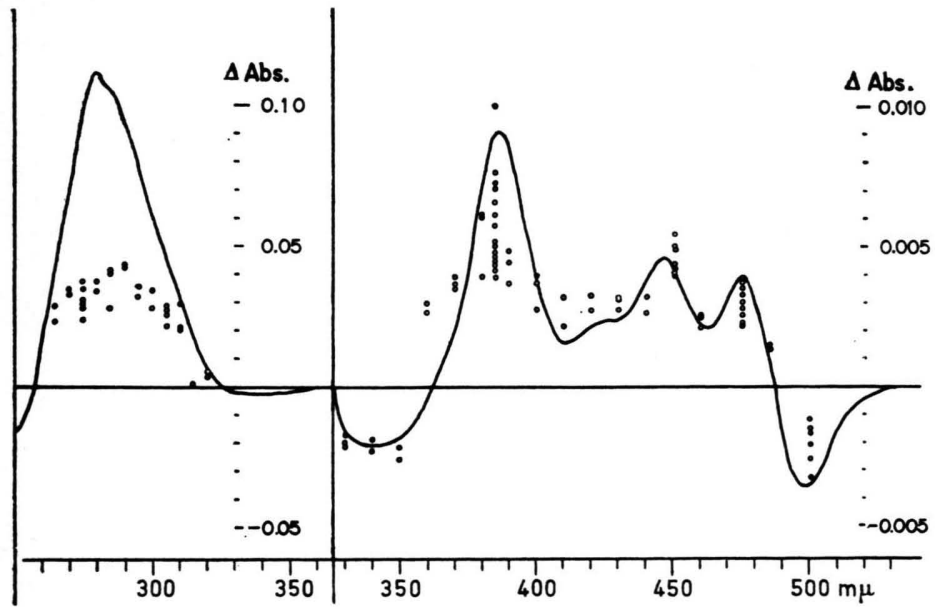

* Figs. 1 and 2 see table page 1174 a.
Fig. 3. Spectrophotometric assignment of the reaction intermediate on the formation of the Eox-S complex of $p$-hydroxybenzoate hydroxylase. The total absorbance changes corrected for the dead-time of the apparatus were obtained from the stopped-flow traces at various wavelengths assuming that the reaction follows a simple bimolecular mechanism. The measurements of the difference spectrum and the absorbance changes on the stopped-flow apparatus were made by the mixing of holoenzyme (Eox: $90 \mu \mathrm{M}$ ) with $p$-hydroxybenzoate (S: 200 $\mu \mathrm{M})$ in $0.05 \mathrm{M}$ phosphate buffer, $\mathrm{pH} 8.2$ (light path: $2 \mathrm{~mm}$ ). 
curred within the dead-time. This indicate that the Eox-S formation is not a simple bimolecular reaction, but contains very rapid absorbance changes in UV region which precedes the changes in visible region.

This conclusion was confirmed by the dependency of the relaxation time, $\tau^{* *}$ on the substrate concentration. The standard procedure for the relaxation method ${ }^{10}$ can be employed for the analysis of the results, since the reaction is reversible. If the Eox-S formation follows a simple bimolecular reaction,

$$
\text { Eox }+\mathrm{S} \underset{k_{2}}{\stackrel{k_{1}}{\rightleftharpoons}} \text { Eox }-\mathrm{S}
$$

a single relaxation time can be observed and the relaxation equation is

$$
1 / \tau=k_{2}+k_{1}\left(\bar{c}_{\mathrm{e}}+\bar{c}_{\mathrm{s}}\right)
$$

$\tau$ was estimated from the half-time of the stoppedflow traces near equilibrium and $\left(\bar{c}_{\mathrm{e}}+\bar{c}_{\mathrm{s}}\right)$ is the sum of the concentrations of free Eox and $S$ at equilibrium which were calculated from the $K_{\mathrm{s}}$, the dissociation constant estimated from the spectrophotometric titration $(26 \mu \mathrm{M}){ }^{11}$. The experimental results were, however, could not be explained by Eqn. (2), since the saturation curve was obtained, as shown in Fig. 4. Therefore, it is conceivable that the Eox-S formation consists of at least two steps as indicated

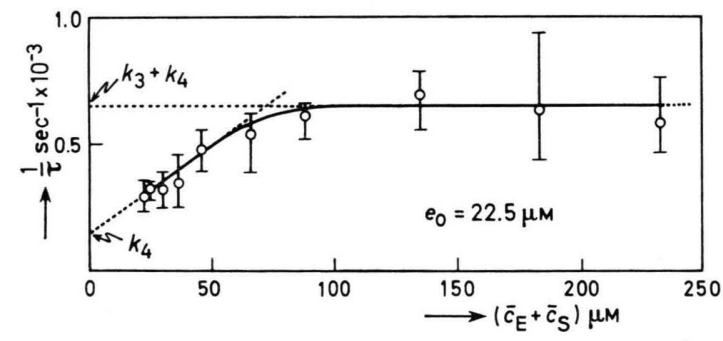

Fig. 4. $1 / \tau_{2} v s\left(\bar{c}_{e}+\bar{c}_{\mathrm{s}}\right)$ plot of the Eox-S formation. The holoenzyme solution $(45 \mu \mathrm{M})$ of $p$-hydroxybenzoate hydroxylase was mixed with an equal volume of substrate solutions $(2.5-500 \mu \mathrm{M})$ at various concentrations. The absorbance changes were followed with the stopped-flow apparatus at $300 \mathrm{~nm}$. The relaxation time $\left(\tau_{2}=t_{1 / 2} / \ln 2\right)$ was estimated from the half-time $(t 1 / 2)$ of the flow traces near equilibrium. The values of $\left(\bar{c}_{\mathrm{e}}+\bar{c}_{\mathrm{s}}\right)$, the sum of the concentrations of free Eox and $\mathrm{S}$ at equilibrium, calculated from the dissociation constant $\left(K_{\mathrm{S}}: 26 \mu \mathrm{M}\right) . k_{3}+k_{4}: 620 \mathrm{sec}^{-1}$ from the saturated level, $k_{4}$ : $140 \mathrm{sec}^{-1}$ from the intercept on ordinate.

\footnotetext{
** The relaxation time $\tau$ was calculated from the half-time of the reaction by the use of the equation, $\tau=t 1 / 2 / \ln 2$. The half-time of the reaction was obtained from the latter phase of the reaction curve (near equilibrium) for which the time course followed the first-order kinetics.
}

by the results in Fig. 3: a rapid reaction which is followed by a slower reaction,

$$
\mathrm{Eox}+\mathrm{S} \underset{k_{2}}{\stackrel{k_{1}}{\rightleftharpoons}} \mathrm{Eox} \sim \mathrm{S} \underset{k_{4}}{\stackrel{k_{3}}{\rightleftharpoons}} \operatorname{Eox}-\mathrm{S} .
$$

In this case two relaxation times, $\tau_{1}$ and $\tau_{2}$, are given Eqns. (4,5), respectively.

$$
\begin{array}{r}
1 / \tau_{1}=k_{1}\left(\bar{c}_{\mathrm{e}}+\bar{c}_{\mathrm{s}}\right)+k_{2} \\
1 / \tau_{2}=k_{4}+\frac{k_{3}\left(\bar{c}_{\mathrm{e}}+\bar{c}_{\mathrm{s}}\right)}{K_{1}+\left(\bar{c}_{\mathrm{e}}+\bar{c}_{\mathrm{s}}\right)}
\end{array}
$$

where $K_{1}=k_{2} / k_{1}$. Experimental results (Fig. 4) is consistent with the Eqn. (5) which can show a saturation curve with respect to $\left(\bar{c}_{\mathrm{e}}+\bar{c}_{\mathrm{s}}\right)$.

The results obtained in the present study on the complexing between Eox and $\mathrm{S}$ is, therefore, consistent with the two-step mechanism [Eqn. (3)], where the first step (Eox $+\mathrm{S} \rightleftharpoons \operatorname{Eox} \sim \mathrm{S})$ is much faster than the second unimolecular step $(E o x \sim S$ $\rightleftharpoons$ Eox-S). The stopped-flow method offered us to observe $\tau_{2}$ alone and $\tau_{1}$ is short to be observed. The value of $k_{4}$ was estimated to be $140 \mathrm{sec}^{-1}$ from the vertical intercept, and $k_{3}$ was estimated to be 480 $\mathrm{sec}^{-1}$ from the saturated level $\left(k_{3}+k_{4}\right)$ minus $k_{4}$.

Eox $\sim S$ in Eqn. (3) is an intermediate complex rapidly formed by the association of Eox and S. The absorbance spectrum of Eox $\sim \mathrm{S}$ was different from the Eox only in UV region. The Eox-S complex which is derived from the Eox $\sim \mathrm{S}$ within a few milliseconds is the enzyme-substrate complex whose absorption spectrum is different from Eox in the visible and UV regions.

The multi-step interaction between the enzyme and its substrate analogs or its effector has been found by means of the temperature-jump method for the ribonuclease-cytidine- $3^{\prime}$-phosphate system ${ }^{12}$, the chymotrypsin-proflavin system (competitive inhibitor) ${ }^{13}$, the aspartate transcarbamirase- $5^{\prime}$-bromocytidine system ${ }^{14}$ and the lysozyme-oligosaccharide system ${ }^{15}$. In these systems it has been reported that the reaction involves a unimolecular process that is attributed to isomerization of the enzyme-substrate (analog) complex or conformational change of the enzyme.

In the case of $p$-hydroxybenzoate hydroxylase, the second unimolecular step in Eqn. (3) may involve the changes in protein conformation and in the FAD moiety, and the velocity of which was rapid enough to explain the overall reaction. 
N. Higashi, H. Shoun, K. Yano, K. Arima, and K. Hiromi, Kinetic Studies on the Enzyme-substrate Complex Formation of p-Hydroxybenzoate Hydroxylase by the Stopped-flow Method (S. 1172)

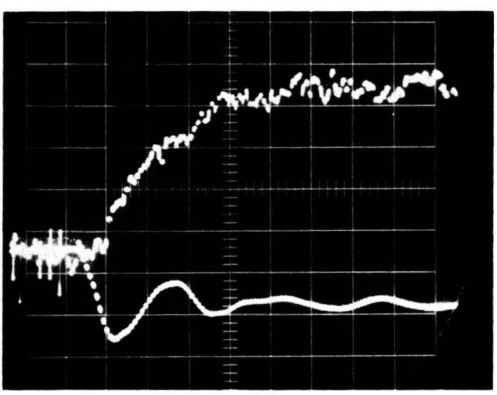

Fig. 1. Stopped-flow trace of ES-complex formation of $p$-hydroxybenzoate hydroxylase (Absorbance change). Upper curve: absorbance change by the mixing of equal volume of Eox $(45 \mu \mathrm{M})$ with $p$-hydroxybenzoate $(200 \mu \mathrm{M})$. Upper direction is the increase in absorbance at $300 \mathrm{~nm}$. Lower trace: a record of the flow speed. Scanning speed: 1 msec per major division. Signal sensitivity: $0.007 \triangle O D$ at $300 \mathrm{~nm}$ per major division.

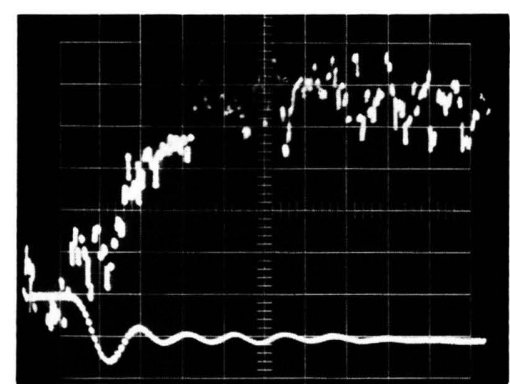

Fig. 2. Stopped-flow trace of ES-complex formation of $p$-hydroxybenzoate hydroxylase (Quenching of fluorescence intensity). Upper curve: Quenching of fluorescence of holoenzyme (FAD moiety) by the mixing of equal volume of Eox $(43 \mu \mathrm{M})$ with $p$-hydroxybenzoate solution $(200 \mu \mathrm{M})$. Lower trace: a record of the flow speed $(18 \mathrm{ml} / \mathrm{sec})$. Scanning speed: $1 \mathrm{msec}$ per major division. Signal sensitivity: 0.01 volt per major division. 

This investigation was supported by the Scientific Research Found from the Ministry of Education of Japan.

1 K. Yano, N. Higashi, and K. Arima, Biochem. biophysic. Res. Commun. 34, 1 [1969].

2 N. Higashi, H. Shoun, K. Yano, and K. Arima, Agr. Biol. Chem. 36, (6), 1081 [1972].

3 K. Yano, N. Higashi, S. Nakamura, and K. Arima, Biochem. biophysic. Res. Commun. 34, 277 [1969].

4 S. Nakamura, Y. Ogura, K. Yano, N. Higashi, and K. Arima, Biochemistry 9, 3235 [1969].

5 N. Higashi, S. Nakamura, K. Yano, and K. Arima, Agr. Biol. Chem. 34, 964 [1970].

6 S. Nakamura, Y. Ogura, K. Yano, N. Higashi, and K. ARIMA, "Flavins and Flavoproteins" (third International Symposium, ed. by H. Kamin), University Park Press Butterworths.

7 N. Higashi, H. Shoun, K. Hiromi, K. Yano, and K. Arima, J. Biochem. 67, 749 [1970].
We want to thank Prof. S. ONO, the University of Osaka Prefecture, and his coworkers for the use of the stopped-flow apparatus. Thanks are also due to Dr. S. NAKAmura for his stimulating and helpful discussions.

8 K. Hiromi, S. Ono, S. Itoh, and T. Nagamura, J. Biochem. 64, 897 [1968].

9 K. Hiromi, Bunkō Kenkyū (in Japanese) 19, 321 [1970].

10 M. Eigen and L. DE MAYer, Techniques of Organic Chemistry, ed. by A. Weissberger et al., Vol. III, part two, p. 895, Interscience Publishers, New York 1963.

11 K. Hiromi and N. Higashi, "Flavoenzymes", ed. by K. YAGI and T. Yamano, in Japanese, Asakura shoten (To kyo), in press.

12 G. G. Hammes and R. E. Cathou, J. Amer. chem. Soc. 86, 3240 [1964].

13 B. H. Haysteen, J. biol. Chemistry 242, 769 [1967].

14 J. Eckfeldt, G. G. Hammes, S. C. Mahr, and Cheng-Wen Wu, Biochemistry 9, 3353 [1970].

15 E. Holler, J. A. Ruply, and G. P. Hess, Biochem. biophysic. Res. Commun. 37, 423 [1969].

\title{
Zur Reduzierbarkeit der Vitamin $B_{12}$-Arten durch Kohlenmonoxid
}

\author{
About the Reduction of the $\mathrm{B}_{12}$-vitamins by Carbon Monoxide \\ MATTHÄUs MOSKOPHIDIS und WILHELM FRIEDRICH \\ unter Mitarbeit von Christa-Maria PoHL \\ Physiologisch-Chemisches Institut der Universität Hamburg \\ (Z. Naturforsch. 27 b, 1175-1182 [1972] ; eingegangen am 23. Mai/10. Juli 1972) \\ Vitamin $\mathrm{B}_{12}$, carbon monoxide, absorption spectra, reduction
}

\begin{abstract}
The reduction by $\mathrm{CO}$ of diaquo-cobinamide, diaquo-cobyric acid and several complete aquocorrinoids in aqueous solutions was studied. Aquo-cobalamin-lactam and all the other corrinoids under study were reduced to $(\mathrm{Co} I \mathrm{II})$. At $37^{\circ} \mathrm{C}$ the reaction is about two to three times faster than at $22{ }^{\circ} \mathrm{C}$, and it is inhibited by benzimidazole and (more strongly) by histidine. CO is a better reductans for diaquo-cobinamide and diaquo-cobyric acid than for the complete corrinoids. Corrinoids with a purine base are more quickly reduced than those with a benzimidazole base. The experiments show that the reaction of $\mathrm{CO}$ with corrinoids is inhibited or delayed by those trans ligands, which are strong electron donors.
\end{abstract}

Die Reaktion der Vertreter des Vitamins $\mathrm{B}_{12}$ mit CO ist beeinflußbar durch a) Strukturmerkmale des Substrates (Wertigkeit des Kobaltatoms; Struktur der Axialliganden; Beschaffenheit des Corrinringes), b) Lösungsmittel (Alkohole bzw. Wasser; pH; in Wasser gelöste potentielle Ligandmoleküle) und c) Temperatur. Die Reaktion läuft nach dem Schema (1) ab:

$$
(\mathrm{Co})^{+}+\mathrm{XO}^{-}+\mathrm{CO} \rightarrow(\mathrm{Co}), \quad \mathrm{X}=\mathrm{H} \text { oder ein Alkyl. }
$$

Sonderdruckanforderungen an Prof. Dr. W. FRIEDRICH, Universitäts-Krankenhaus Eppendorf, Physiolog.-Chem. Institut d. Univ., D-2000 Hamburg 20, Martinistr. 52.
In Alkoholen (vor allem in Methanol) als Lösungsmittel bildet sich ein stabiles Produkt, das Alkoxycarbonyl-corrinoid (Schema 1, X=Alkyl) ${ }^{1,2}$. (Co) steht hier zumeist für komplette (nucleotidhaltige) Aquo-corrinoide bzw. für inkomplette Diaquo-corrinoide, obwohl unter gewissen Bedingungen auch Cyano-corrinoide reagieren können ${ }^{2}$.

Die Tatsache, daß $\mathrm{B}_{12}$-Arten in der Lactam-Form ${ }^{3}$ unter gewissen Bedingungen schlechter als native $\mathrm{B}_{12}$-Arten mit $\mathrm{CO}$ und Methanol reagieren ${ }^{1,2}$, dürfte auf sterische Einflüsse (Sperrigkeit der Methoxycarbonyl-Gruppe) zurückzuführen sein. Dies steht im Einklang mit der Beobachtung, daß in höhermolekularen Alkoholen die Reaktionsausbeute 